\title{
Competências relevantes para a efetividade do processo decisório em defesa aérea*
}

\author{
Lucia Helena Martins Silva** \\ Karina De Dea Roglio*** \\ Wesley Vieira Silva****
}

SumÁrio: 1. Introdução; 2. Revisão bibliográfica; 3. Aspectos metodológicos; 4. Apresentação e análise dos resultados; 5. Discussão dos resultados; 6. Considerações finais.

Summary: 1. Introduction; 2. Literature review; 3. Methodological aspects; 4. Results and analysis; 5 . Discussion of the results; 6 . Final remarks.

Palavras-chave: Organização militar; processo decisório; competências.

KEY WORDS: Military organization; decision-making process; competences.

Este artigo investiga o impacto das competências consideradas essenciais para o desempenho das atividades de defesa aérea sobre a efetividade do processo decisório. Como principais referenciais teóricos, foram utilizados os estudos de Simon (1970; 1987) sobre o processo decisório e o modelo de competências por setor de Gramigna (2002). Na pesquisa de campo, utilizou-se a triangulação de dados: entrevistas, análise documental, observações e questionário, por meio do qual levantou-se a percepção dos profissionais que desempenham as funções em estudo. Os dados foram analisados através de análise fatorial exploratória e análise de regressão linear múltipla. Os

\footnotetext{
* Artigo recebido em set. 2007 e aceito em fev. 2009.

** Psicóloga, mestranda no Programa de Pós-Graduação em Administração da Pontifícia Universidade Católica do Paraná (PUC-PR). Endereço: Av. Imaculada Conceição, 1155 — CEP 80215-901, Curitiba, PR, Brasil. E-mail: luciahms@hotmail.com.

*** Doutora em engenharia de produção pela Universidade Federal de Santa Catarina. Professora do Programa de Pós-Graduação em Administração da Universidade Federal do Paraná (UFPR). Endereço: Av. Professor Lothário Meissner, 632 - SCSA - CEP 80210-170, Curitiba, PR, Brasil. E-mail: karinaroglio@gmail.com.

**** Doutor em engenharia de produção pela Universidade Federal de Santa Catarina. Professor do Programa de Pós-Graduação em Administração da PUC-PR. Endereço: Av. Imaculada Conceição, 1155 — CEP 80215-901, Curitiba, PR, Brasil. E-mail: wesley.vieira@pucpr.br.
} 
resultados da pesquisa realizada para este artigo contribuem para o estabelecimento de programas voltados ao desenvolvimento de competências individuais específicas, com impacto direto nas competências essenciais da organização. Os achados deste artigo servem também aos gestores militares como subsídio para decisões relativas à alocação de pessoal e formação de equipes, visando distribuir de forma mais racional os indivíduos, aliando suas competências aos interesses organizacionais, tal seja, alinhando as práticas de gestão de pessoas à estratégia organizacional.

Relevant competences for an effective decision-making process in air defense This article discusses the impact of the air defense core competences on the effectiveness of the decision-making process. Its theoretical framework includes Simon's studies on the decision-making process (1970; 1987), Gramigna's model of competences by industry (2002), and an empirical study based on interviews, document analysis, observations, and a questionnaire distributed to 21 officers from the Integrated Air Defense and Traffic Control Center (Cindacta). The data collected was analyzed through factorial analysis and multiple linear regression. The findings contribute to the organization of training programs that focus on the development of specific individual skills that influence the organization's core competences. They can also be used by military staff to support decisions on personnel allocation and team building, in order to link human resources practices to organizational strategy.

\section{Introdução}

Algumas profissões são desconhecidas do público em geral, incluindo-se aqui a maioria das atividades militares. Isto se deve, em parte, pela especificidade das próprias atividades, mas também pela necessidade de sigilo quanto aos conhecimentos e técnicas empregados, visando garantir o fator surpresa diante do inimigo. Neste artigo, optou-se por focar nas atividades de Defesa Aérea, executadas por militares nos centros de operações militares.

O Departamento de Controle do Espaço Aéreo (Decea), órgão subordinado ao Comando da Aeronáutica, é responsável por garantir as condições de navegabilidade no espaço aéreo, bem como defender a soberania nacional. Tais prerrogativas são executadas a partir de quatro centros integrados de defesa aérea e controle de tráfego aéreo (Cindacta). Nessas unidades, em locais distintos, operam controladores responsáveis pelos fluxos da aviação civil e pelo tráfego militar, estes últimos alocados nos centros de operações militares (COpM).

A relevância do artigo repousa exatamente nas características intrínsecas às atividades de alta complexidade e precisão que costumam restringir-se a treinamentos rotineiros, mas tem potencial para atingir a proporção de tra- 
gédia, como a ocorrida em 1988, quando um cruzador de mísseis da Marinha americana derrubou um avião de passageiros iraniano, matando 290 civis a bordo, em decorrência de ter acidentalmente o identificado como hostil (Spector, 2004).

A importância do estudo do processo decisório no contexto da defesa aérea é notória, em especial ao levar-se em consideração a vigência da Lei no 9.614/1988, popularmente conhecida como Lei do Abate, que regulamentou os procedimentos para identificação, alerta e destruição de aeronaves consideradas ilícitas. Além de agregar conhecimentos à pesquisa sobre processo decisório, tal investigação é considerada uma valiosa ferramenta para futuras decisões por parte dos gestores militares. Obviamente que o contexto de organização militar restringe a implementação da gestão por competências nos moldes que vêm sendo propostos pela maioria dos estudos e empresas de consultoria, mas não inviabiliza a construção de um modelo que possa ser adequado às especificidades da atividade.

Conduziu-se o artigo em uma organização militar, com o objetivo de avaliar o impacto das competências consideradas essenciais para o desempenho das atividades de defesa aérea sobre a efetividade do processo decisório, na percepção dos profissionais que desempenham as funções em estudo.

Para atingir tal objetivo, elaborou-se, inicialmente, uma seção na qual são revisados os principais conceitos contemplados no artigo: processo decisório e competências. Seguiu-se, então, com a exposição da metodologia empregada na pesquisa. Na seção seguinte, foram apresentados e discutidos os resultados encontrados e, numa última seção, foram feitas considerações a respeito deste e de futuros artigos, no sentido de contribuir para a construção de um modelo que atenda às necessidades de um órgão de controle de operações militares.

\section{Revisão bibliográfica}

Nesta seção são apresentados os principais conceitos explorados neste artigo: processo decisório e competências.

\section{Processo decisório: da exatidão à complexidade}

Para Barnard (1979), precursor dos estudos sobre processo decisório nas organizações, a tomada de decisão é baseada em fatos que resultam de delibe- 
ração, cálculo e pensamento. Considera, portanto, que, devido à inserção da decisão em um contexto formalmente estabelecido, os processos que a compõem são, necessariamente, processos lógicos, em oposição às decisões no nível individual, essas sim afetadas pela emoção do indivíduo.

Outros estudos apresentam modelos que se propõem a representar o processo decisório. O modelo de decisão racional, baseado em cálculos oriundos da economia, considera os objetivos claramente definidos e o ambiente basicamente estável, sendo bastante aceito no meio acadêmico e na sociedade. Sob essa perspectiva, o processo sempre ocorre em fases perfeitamente distinguíveis: diagnóstico do problema, levantamento das ações possíveis, avaliação das implicações de cada ação e escolha por aquela que maximiza os resultados. Constata-se o caráter normativo do modelo, por pressupor que os decisores são sempre consistentes em seus julgamentos, seguem procedimentos linearmente definidos para tomar decisões, buscam maximizar a utilidade de cada alternativa e podem calcular tanto as consequências dos planos de ação quanto as suas probabilidades associadas (Antonacopoulou e Papamichail, 2004).

A essa lógica se contrapuseram estudos que incluíam outros aspectos na análise do processo decisório. Ainda na década de 1960, Herbert Simon destacou-se com sua concepção de racionalidade limitada, ao afirmar que, mesmo utilizando-se de ferramentas lógicas, a própria cognição humana contém aspectos de subjetividade, os quais o homem não pode neutralizar em sua percepção e julgamento. Com isso, frisou a importância da cognição no processo que conduz à escolha.

Mintzberg e colaboradores (1976:246) definiram processo decisório como "um conjunto de ações e fatores dinâmicos que inicia com a identificação do estímulo para a ação e finaliza com o compromisso específico de agir". Entre 12 fatores referentes ao processo, considerou, sob impacto dos estudos acerca da cognição humana, cinco fases relativas ao processamento das informações:

v atenção - na qual ocorre o reconhecimento de algo que merece atenção;

v codificação - é uma fase de diagnóstico, na qual a situação é definida;

v armazenamento/recuperação - etapa na qual se pode procurar soluções prontas, modificar soluções existentes ou desenvolver novas soluções;

v escolha - na qual se tem uma opção única, a ser aceita ou rejeitada ou um conjunto de ações potenciais, que exigem escolha, não sem conflito de interesses;

v resultados — após a decisão, ocorre uma rotina de autorização. 
A principal diferença entre esse modelo e o racional está na possibilidade de criação de soluções, por parte do decisor; aquele considerava haver uma única solução correta, que deveria ser encontrada.

Atualmente se observa, por um lado, uma revitalização da ideia de racionalidade analítica no processo decisório, decorrente do uso intensivo dos sistemas de informação (Motta, 1996) e, por outro lado, uma disseminação das concepções holística e sistêmica, a partir das quais o indivíduo que toma a decisão deve ser considerado em suas particularidades (personalidade, experiências, crenças, valores etc.) e, ao mesmo tempo, na totalidade de suas relações com o meio e com os demais indivíduos. Sob tal ótica, mesmo quem decide intuitivamente não deixa de se guiar pela lógica, que pode ser subjetiva, mas envolve a dimensão racional e também quem decide racionalmente é afetado pelos valores, crenças e experiências de vida de quem decide.

Assim, espera-se que o gestor esteja habilitado a fazer uso das ferramentas de apoio à decisão, que permitem o processamento de um grande volume de dados e, ao mesmo tempo, que busque no cotidiano as experiências e informações para basear suas decisões, reexaminando-as constantemente, em busca de novos valores e novas práticas.

Neste artigo optou-se por utilizar no instrumento de coleta de dados a classificação defendida por Simon (1970), que identificou a existência de quatro momentos durante o processo decisório:

v fase de inteligência - na qual ocorre a exploração do ambiente;

v fase de concepção - abrange a criação e a análise dos possíveis cursos de ação;

v fase de escolha - em que há a opção por uma das alternativas de ação;

v fase de revisão — na qual são avaliadas decisões tomadas anteriormente.

Estas fases estão presentes em qualquer tipo de decisão, independentemente de características específicas, como aquelas ligadas ao nível administrativo em que ocorre. Para Simon (1987), quanto mais alto o nível hierárquico, mais estratégico é o caráter das decisões a serem tomadas, como se observa em sua classificação:

- nível operacional — as decisões são compostas por ações previamente selecionadas;

v nível tático - as decisões relacionam-se com o controle administrativo;

v nível estratégico - as decisões envolvem maior volume de informações, pois nortearão as ações da organização. 
Simon (1970) classificou, ainda, as decisões em programadas e não programadas, sendo as primeiras repetitivas e rotineiras, portanto passíveis de resolução através de procedimentos já estabelecidos; enquanto as não programadas referem-se a situações novas, têm consequências distintas das usuais, exigindo julgamento por parte do tomador de decisões. A capacidade de julgamento, segundo o autor, está diretamente ligada à criatividade, discernimento e intuição. É nessa relação estabelecida por Simon entre habilidades do indivíduo e capacidade de tomar decisões efetivas que se baseia a escolha do referido modelo como norteador deste artigo.

Apesar da crescente utilização de ferramentas de apoio à decisão, elas não dão conta da complexidade dos fatores que compõem as decisões não programadas. Gramigna (2002) afirma que o processo de decisão é afetado pelo nível de conhecimento exigido para o desempenho das funções. Entendese, entretanto, que não apenas os conhecimentos impactam a efetividade do processo decisório, mas o conjunto de conhecimentos, habilidades e atitudes dos sujeitos, que compõem as chamadas competências individuais. Cabe, portanto, revisar tal conceito, com o objetivo de compreender como agrega valor à organização, capacitando-a a atingir seus objetivos.

\section{Competências: do cargo à capacidade de agregar valor}

A Escola de Administração Científica trouxe a noção de ajuste do trabalhador ao cargo, como forma de atingir os resultados organizacionais. Assim, da análise detalhada de uma atividade provinham informações acerca das características individuais preditoras de bom desempenho, já que a eficiência garantia à organização espaço no mercado. Segundo Lawler III (1994), o entendimento corrente era de que os indivíduos agregavam valor na medida em que se ajustavam à estrutura organizacional.

Por sua vez, a visão clássica de estratégia organizacional, com seu expoente máximo em Porter, privilegia a análise dos fatores externos à organização como fonte de vantagem competitiva. A pretensão por ajustamento do homem a forças externas guiou a maioria das práticas relativas a recursos humanos nas organizações. Entretanto, como bem aponta Teece, citado por Stewart (1998:13):

Mudanças fundamentais foram moldadas na economia global e estão mudando as bases do nível de vantagem competitiva de empresas... expondo um novo núcleo fundamental como base para a criação de riqueza. O núcleo fundamental 
é o desenvolvimento e a formação e utilização inteligente de ativos intangíveis, entre os quais o conhecimento, competência e propriedade intelectual são os mais importantes.

Assim, não mais a eficiência, mas a capacidade de mover-se no ambiente instável, atualizando seus saberes e mesmo modificando sua estrutura passou a conferir às organizações competitividade. Tal perspectiva está presente nos preceitos da visão baseada em recursos (VRB), inicialmente proposta por Barney (1991). Posteriormente, estudos empreendidos por Barney e Arikan (2001) comprovam que a posse de recursos superiores pode ser fonte de vantagem competitiva. De acordo com esses autores, os recursos podem ser de cinco tipos: (1) financeiros, relativos aos recursos monetários; (2) físicos, compreendendo as instalações e equipamentos; (3) humanos, englobando a forma de organização e também as habilidades, formação e treinamento dos membros da organização; (4) conhecimento e aprendizagem organizacional; (5) organizacionais gerais, incluindo reputação, patentes e relações com stakeholders.

De acordo com Harrison (2005), a capacidade de um recurso em gerar vantagem competitiva sustentável ocorre na medida em que ele: (1) tiver valor no mercado; (2) for único; (3) difícil de ser imitado; (4) não houver substitutos disponíveis para ele no mercado. Além do mais, é necessário que a empresa reconheça essas vantagens e tenha condições de aproveitá-las em suas atividades. $\mathrm{O}$ autor afirma que "a maioria das empresas muito bem-sucedidas ao longo prazo efetivamente adquirem, desenvolvem e administram recursos e capacidades que geram vantagens competitivas" (Harrison, 2005:26). Na visão de Hamel e Prahalad (2005), é necessário desenvolver um conjunto único de tecnologias e habilidades específicas, as chamadas competências essenciais, que propiciem à organização entrar e se manter no mercado, além de criar novos produtos.

A visão baseada em recursos, portanto, trouxe a perspectiva da própria empresa operacionalizar e sustentar vantagem competitiva, a partir do arranjo de seus recursos físicos, financeiros, intangíveis ou humanos. As competências essenciais são, portanto, construídas a partir das competências individuais de seus membros, como apontam Moura e Bitencourt (2006) ao afirmar que a efetividade de uma organização depende de sua capacidade de articular o direcionamento estratégico com as competências organizacionais e individuais de seus membros. Nesse contexto, os funcionários - neste caso o efetivo de militares - adquirem importância estratégica, pois deles e da forma de administrá-los depende a excelência nas atividades desenvolvidas pela organização. 
À medida que as tradicionais fontes de vantagem competitiva não se mostraram suficientes, os indivíduos e suas competências passaram a ser enfatizados como elementos centrais de diferenciação estratégica. Tal perspectiva implica que do indivíduo passou a ser esperado não mais o ajustamento, mas a capacidade de transformação. $O$ indivíduo sofre alterações profundas em sua identidade, tornando-se o trabalhador do conhecimento, conforme o saber tornou-se o principal fator de produção (Stewart, 1998:63).

Apesar do conceito de competência não ser novo e abarcar muitas divergências no que tange ao seu significado, pode-se verificar que competência usualmente refere-se a um conjunto de características - conhecimentos, habilidades e atitudes - capazes de produzir resultados (Dutra, 2004; Gramigna, 2002; Gomes, 2003; Spector, 2004). Dutra (2004) conceitua competência individual como a capacidade de mobilizar conhecimentos, recursos e habilidades que agreguem valor econômico à organização e também valor social ao indivíduo.

Neste artigo optou-se por utilizar a posição de Gramigna (2002), uma vez que a autora realizou mapeamento de competências em diversos setores da economia brasileira, inclusive no setor público, no qual se insere a organização estudada.

Note-se que este setor tem características próprias e vem passando por um processo de mudança cultural importante, na medida em que transita "do modelo burocrático controlador de processos para o modelo gerencial controlador de resultados" (Felix, 2005:256). De acordo com Souza (2002), o governo passou a considerar estratégia para essa transformação a capacitação de seus servidores, além da valorização da função pública e da realização de avaliações de desempenho regulares.

Como resultado do estudo de Gramigna (2002), a partir de mais de 4.500 perfis, foram elencadas como competências essenciais para a empresa pública aquelas descritas no quadro.

\section{Competências relevantes para a eficiência do setor público}

- Capacidade empreendedora - facilidade para identificar novas oportunidades de ação, propor e implementar soluções aos problemas e necessidades que se apresentam, de forma assertiva, inovadora e adequada.

- Capacidade de trabalhar sob pressão - capacidade para selecionar alternativas de forma perspicaz e implementar soluções tempestivas diante de problemas identificados, considerando suas prováveis consequências.

- Comunicação - capacidade de ouvir, processar e compreender o contexto da mensagem, expressar-se de diversas formas e argumentar com coerência usando o feedback de forma adequada, para facilitar a interação entre as partes. 
- Criatividade - capacidade para conceber soluções inovadoras viáveis e adequadas para as situações apresentadas.

- Flexibilidade - habilidade para adaptar-se oportunamente às diferentes exigências do meio e capacidade de rever postura diante de argumentações convincentes.

- Liderança - capacidade para catalisar os esforços grupais, a fim de atingir ou superar os objetivos organizacionais, estabelecendo um clima motivador, formando parcerias e estimulando o desenvolvimento da equipe.

- Motivação - capacidade de demonstrar interesse pelas atividades a serem executadas, tomando iniciativas e mantendo atitude de disponibilidade, e de apresentar postura de aceitação e vitalidade, que indica energia para os trabalhos.

- Negociação - capacidade de expressar e de ouvir o outro, buscando equilíbrio de soluções satisfatórias nas propostas apresentadas pelas partes, quando há conflitos de interesse, e de observar o sistema de trocas que envolve o contexto.

- Planejamento - capacidade para planejar o trabalho, atingindo resultados por meio do estabelecimento de prioridades, metas tangíveis, mensuráveis e dentro de critérios de desempenho válidos.

- Visão sistêmica - capacidade para perceber a integração e interdependência das partes que compõem o todo, visualizando tendências e possíveis ações capazes de influenciar o futuro

- Relacionamento interpessoal - habilidade para interagir com as pessoas de forma empática, inclusive diante de soluções conflitantes, demonstrando atitudes positivas, comportamentos maduros e não combativos.

Fonte: Adaptado de Gramigna (2002).

Em um estudo acerca da prática de competências gerenciais no setor público, Felix (2005:261) identifica algumas competências similares às listadas no quadro: delegar poder a funções (empowerment), unidades ou órgãos em contato direto com a população; criar um ambiente de confiança e comprometimento; visualizar globalmente a realidade e o problema; efetuar análise conjunta e decidir em colegiado; desenvolver trabalho em equipe e mediar conflitos; acompanhar a execução do plano de trabalho e analisar a adequação das estratégias utilizadas; levantar potencial de parcerias.

Quanto ao aspecto militar, cabe aqui destacar o alerta de Jordan (2007) acerca dos benefícios da troca de experiências entre os setores civis e militares da sociedade. Apesar da impossibilidade de generalização das práticas do setor civil ao militar, existem pontos de excelência em cada um deles que merecem atenção por parte dos gestores e pesquisadores. Tal apontamento justifica inclusive a importância de serem realizados estudos em organizações militares que, segundo a autora, tem como principal diferencial a liderança precoce, a proximidade e a comunicação que os líderes mantêm com seus subordinados, além da existência de um núcleo de valores fortemente compartilhado na organização. 


\section{Aspectos metodológicos}

Nesta seção apresenta-se a metodologia utilizada no artigo, subdividia em quatro subseções que retratam a caracterização da pesquisa, coleta e tratamento dos dados, os métodos de análise empregados e a contextualização do estudo de caso.

\section{Caracterização da pesquisa}

Levando-se em conta a natureza do fenômeno estudado e os objetivos do artigo, optou-se por realizar um estudo de caso em uma organização militar de defesa aérea, localizada em Curitiba, estado do Paraná. Conforme apontado por Yin (2001), o estudo de caso pode ser visto como uma investigação empírica, que procura entender um fenômeno contemporâneo dentro de um contexto real, principalmente no que se refere a situações nas quais os limites entre os fenômenos e o contexto não estão claramente definidos.

Este artigo ainda se caracteriza como uma pesquisa quantitativa, definida por Godoy (1995) como aquela cujo ponto de partida é um plano que detalha antecipadamente as variáveis, visando mensurá-las e quantificar os resultados. Sua natureza é descritiva, uma vez que visa estabelecer relações entre variáveis por meio da descrição das características de determinado fenômeno ou população (Gil, 2002).

\section{Coleta dos dados}

Inicialmente, foram realizadas entrevistas semiestruturadas com pessoas-chave do Centro de Operações Militares sediado na organização estudada, visando levantar as competências consideradas essenciais para o bom desempenho das funções que o integram: controlador de tráfego aéreo militar (Ctam), controlador de operações aéreas militares (Coam), ajudante de chefe controlador (AJCC) e chefe controlador (CC). A entrevista semidirigida é recomendada para situações em que o pesquisador não deseja impor a sua visão de realidade, necessitando de uma estratégia mais flexível que propicie a obtenção de informações detalhadas (Richardson, 1985).

Recorreu-se, ainda, à legislação que descreve e estabelece as qualificações necessárias para a habilitação dos indivíduos que exercem essas funções. 
Entretanto, devido ao caráter confidencial dos dados, optou-se por utilizar o conteúdo das entrevistas, questionários e observações, considerando que essa triangulação de dados já atenderia aos objetivos propostos. As observações dos profissionais no exercício de suas funções foram empreendidas em horários e situações diversos e aliadas às informações obtidas nas entrevistas e à revisão teórica dos principais conceitos envolvidos e serviram como base para a construção do questionário.

No questionário, foram relacionadas as fases do processo decisório às competências que, na percepção dos profissionais que desempenham as funções em estudo, impactam a capacidade decisória. Entre as competências apresentadas, 10 (capacidade empreendedora; capacidade de trabalhar sob pressão; comunicação; criatividade; flexibilidade; liderança; motivação; negociação; planejamento e visão sistêmica) foram extraídas do estudo de Gramigna (2002), que as apontou como relevantes à empresa pública (descritas no quadro), e uma, relacionamento interpessoal, foi incluída a partir de necessidade constatada em entrevistas com pessoas-chave do órgão pesquisado e observação in loco da atividade.

Para a definição das quatro fases do processo decisório foram empregados os conceitos de Simon (1970; 1987), considerando-se a existência de quatro momentos, que exigiriam comportamentos distintos ao longo do processo decisório: (1) identificação da necessidade de tomada de decisão; (2) criação e análise dos possíveis cursos de ação; (3) escolha por uma das alternativas de ação; (4) avaliação das decisões tomadas.

O questionário foi elaborado com base numa escala de likert de cinco pontos, com intensidade variando de discordância à concordância. Os 15 itens resultantes no questionário, 11 relativos às competências e quatro às fases do processo decisório, foram submetidos à validação por meio da aplicação individual a uma amostra intencional de trabalhadores que operam o sistema analisado. Como resultado de tal avaliação, realizada a priori, não foram detectados quaisquer tipos de distorções que indicassem necessidade de aprimoramento no instrumento utilizado.

A amostra utilizada para a consecução da pesquisa foi composta por 21 trabalhadores vinculados à atividade de defesa aérea na cidade de Curitiba/PR, cujo universo é de 46 militares. A coleta de dados aconteceu entre os meses de novembro e dezembro de 2006. Para tanto, os profissionais se dispuseram a preencher o instrumento de coleta na presença dos pesquisadores, para que não houvesse eventuais dúvidas sobre os conceitos existentes nas questões formuladas. 


\section{Tratamento e análise dos dados}

Antes de avaliar a base de dados coletada, foi necessário passar por um conjunto de etapas preliminares, de modo a assegurar a validade interna da amostra coletada, a crítica construtiva dos questionários e da digitação, bem como a modelagem por meio da análise fatorial exploratória e da análise de regressão linear múltipla. Os dados foram tratados estatisticamente, valendo-se do software XLSTAT versão 7.5, um pacote adicionado ao Excel, além do pacote SPSS 14.0, com os quais foram realizadas análises com base em estatísticas descritivas e multivariada.

\section{Análise de regressão linear múltipla}

A técnica de análise de regressão linear múltipla é utilizada aqui com o objetivo de avaliar a existência entre duas ou mais variáveis quantitativas de tal forma que uma variável possa ser predita a partir da outra ou das outras.

Assim, parte-se da suposição de que o objetivo seja obter a relação existente entre uma variável qualquer (variável dependente $Y$ ) e outras variáveis (variáveis independentes $\mathrm{X}_{1}, \mathrm{X}_{2}, \mathrm{X}_{3}, \ldots, \mathrm{X}_{\mathrm{k}}$ ). Vale destacar que uma amostra de observações correspondentes às variáveis estudadas deverá ser coletada. Além disso, o número de observações deve ser pelo menos igual ao número de variáveis para que o método possa ser utilizado, pois, caso contrário, é impossível algebricamente estabelecer-se uma solução.

De acordo com Kutner e colaboradores (2005), a regressão linear múltipla visa, entre outras coisas, estabelecer a importância relativa e a magnitude do efeito das variáveis preditoras sobre a variável dependente, identificar preditores que deveriam ser eliminados do modelo e apontar a necessidade de inclusão de variáveis preditoras ainda não participantes do modelo.

\section{Análise fatorial exploratória}

Segundo Hair Jr. e colaboradores (1998), um fator representa uma combinação linear de variáveis originais. A análise fatorial serve para a combinação de variáveis que criam novos fatores. No âmbito da análise fatorial, o que se pretende é a identificação de possíveis associações entre as variáveis observacionais, de modo que se defina a existência de um fator comum entre elas. 
Babbie (1999) afirma que a análise fatorial é uma técnica multivariada que possibilita a identificação de estrutura de inter-relacionamento inerente a um conjunto de dados, identificando fatores que, por sua vez, são dimensões qualitativas, capazes de revelar aspectos comportamentais. Assim, pode-se dizer que a análise fatorial, ou análise de fator comum, tem por objetivo identificar fatores ou constructos subjacentes às variáveis observacionais, o que contribui para facilitar sobremaneira a interpretação dos dados.

O modelo de análise fatorial estima os fatores e as variâncias, de modo que as covariâncias ou as correlações previstas estejam o mais próximo possível dos valores observados. Para tal, os métodos de estimação ou extração mais usados são: o das componentes principais e o da máxima verossimilhança. Neste artigo empregou-se o método das componentes principais.

\section{Contextualização do estudo de caso}

O Centro de Operações Militares estudado é responsável por coordenar as operações militares e patrulhar o espaço aéreo no âmbito de sua área de abrangência, que é a porção sul do país. Para tanto, conta com um efetivo de 46 militares, distribuídos entre as quatro funções: controlador de tráfego aéreo militar (Ctam), controlador de operações aéreas militares (Coam), ajudante de chefe controlador (AJCC) e chefe controlador (CC). O exercício das funções tem estreita relação com a hierarquia: as três primeiras funções são exercidas por graduados (desde terceiro-sargento até suboficial), que perfazem um efetivo de 38 indivíduos de ambos os sexos e a última por oficiais (desde segundotenente até coronel), num total de 8 homens.

Enquanto os graduados pertencentes ao órgão dedicam-se exclusivamente a esse serviço, apenas dois dos oficiais dedicam-se integralmente ao órgão. Os demais trabalham em outros setores da organização, ou mesmo em outras unidades, comparecendo apenas para cumprir os turnos de serviço operacional, considerando que o serviço é prestado ininterruptamente. A assunção das referidas funções depende de formação apropriada, antiguidade, indicação da chefia, aprovação em curso específico e ainda um conselho operacional, em que representantes de diversos setores da organização militar participam para homologar ou não a habilitação do militar à função.

A observação das atividades de defesa aérea, bem como as descrições contidas em legislação e outros estudos a que se teve acesso permitem afirmar que os referidos profissionais, durante o turno de trabalho, encontramse continuamente engajados em processos decisórios. Devido à complexi- 
dade das atividades, há normas que contêm minuciosamente detalhados os procedimentos e a fraseologia a ser empregada na comunicação, visando sempre diminuir a chance de erro humano e elevar os rígidos padrões de segurança.

A atividade não pode ser considerada rotineira, uma vez que os procedimentos operacionais não eximem os controladores do constante processamento de informações, oriundas dos ambientes internos e externos, com vistas à definição de diretrizes de ação que envolvem terceiros. A observação empreendida para este artigo possibilita sintetizar o trabalho do profissional de defesa aérea, sem considerar as especificações técnicas, conforme a seguinte descrição:

v monitoramento do ambiente, a partir de consoles em que são visualizados os sinais emitidos pelos radares e frequências de rádio, com vistas a identificar todas as aeronaves e, no caso de aeronave militar, coordenar o trajeto a ser cumprido por quem as pilota;

v planejamento, a partir de esquemas mentais que permitem antever as situações que se configurarão nos próximos momentos e decidir, com base nas configurações futuras;

v tomada de decisão, na qual define e comunica ao executor que caminho deverá tomar e assume a responsabilidade inerente à complexidade das operações em questão.

Tais tarefas assemelham-se ao que Simon (1970) descreveu ao propor as etapas do processo decisório, permitindo inferir que os indivíduos que as executam necessitam ter desenvolvidas as competências que determinam a eficiência no processo decisório.

Quanto à divisão do trabalho, merece ser destacado que as etapas iniciais do processo decisório ficam a cargo de pessoas que ocupam posições mais baixas na hierarquia (o Ctam e o Coam monitoram e conduzem as aeronaves, enquanto o AJCC supervisiona a operação) ficando a cargo dos oficiais (CC) a fase de tomada de decisão propriamente dita.

\section{Apresentação e análise dos resultados}

Com o objetivo de apresentar e analisar os resultados do trabalho de campo, nesta seção são apresentados o perfil da amostra, os resultados da análise fatorial exploratória e os resultados da análise de regressão linear múltipla. 


\section{Perfil da amostra}

Na tabela 1 são apresentadas as principais estatísticas descritivas das variáveis identificatórias dos 21 sujeitos que compuseram a amostra: idade, posto, tempo total de serviço e tempo de experiência na função.

Tabela 1

Estatística descritiva dos dados de identificação da amostra

\begin{tabular}{|lcccc|}
\hline & Idade & Posto/Graduação & Tempo serviço & Tempo função \\
\hline Média & 29,762 & 2,667 & 11,381 & 4,094 \\
Erro padrão & 1,535 & 0,504 & 1,847 & 1,133 \\
Mediana & 29 & 2 & 10 & 1 \\
Desvio padrão & 7,035 & 2,309 & 8,464 & 5,193 \\
Variância & 49,490 & 5,333 & 71,648 & 26,972 \\
Mínimo & 20 & 1 & 1 & 0,03 \\
Máximo & 42 & 9 & 27 & 16 \\
Nível de confiança (95\%) & 3,202 & 1,051 & 3,853 & 2,364 \\
\hline
\end{tabular}

Observe-se que, para fins de mensuração, foi atribuído um grau a cada um dos postos e graduações, segundo descrito na tabela 2.

Tabela 2

Graus atribuídos aos participantes, conforme posição hierárquica

\begin{tabular}{|lc|}
\hline Posição hierárquica & Pontuação \\
\hline Coronel & 10 \\
Tenente-coronel & 9 \\
Major & 8 \\
Capitão & 7 \\
Primeiro-tenente & 6 \\
Segundo-tenente & 5 \\
Suboficial & 4 \\
Primeiro-sargento & 3 \\
Segundo-sargento & 2 \\
Terceiro-sargento & 1 \\
\hline
\end{tabular}


A análise dos dados de identificação evidenciou, no item referente à posição hierárquica mediana 2 , o que se justifica pela concentração de graduados no exercício efetivo de controle de aeronaves militares. No que concerne ao tempo de serviço, levando-se em conta o tempo mínimo de 30 anos de serviço para o militar, a média 11,381 é um indício de que a maioria das pessoas encontra-se em início de carreira, embora o desvio padrão de 8,464 aponte para um equilíbrio em termos de experiência.

\section{Resultados da análise fatorial exploratória}

Foi realizada a análise da confiabilidade interna dos dados por intermédio da estatística do alfa de Cronback $\left(\alpha_{C}\right)$, que é reconhecidamente a estatística mais popular aos olhos dos pesquisadores. Além disso, avaliou-se se os dados coletados estavam suficientemente ligados para se proceder à análise fatorial.

Para tal utilizou-se o método de Kaiser-Meyer-Olkin measure of sampling adequacy (KMO), que mede a adequação dos dados, em que valores iguais ou menores que 0,5 indicam que a realização da análise fatorial é insatisfatória devido à correlação fraca entre as variáveis. Os valores críticos para a interpretação do teste KMO são:

v em torno de 0,90 — adequação ótima;

v em torno de 0,80 — adequação boa;

、 em torno de 0,70 — adequação razoável;

v em torno de 0,60 — adequação medíocre;

v em torno de 0,50 ou menos — adequação imprópria.

O KMO é um teste que examina o ajuste de dados, tomando todas as variáveis simultaneamente, provendo uma informação sintética sobre os mesmos. Outro teste que precede a análise fatorial com vistas à verificação de suas premissas é o Bartlett test of sphericity (BTS), que testa a hipótese de que a matriz de correlação seja uma matriz identidade (diagonal igual a um e todas as outras medidas iguais a zero), ou seja, que não haja correlação entre as variáveis (Pereira, 2001). Os resultados para o alfa de Cronback $\left(\alpha_{C}\right)$, bem como a estatística KMO, a estatística BTS e o percentual de explicação da variância (PEV) de cada um dos fatores (dimensões) extraídos encontram-se evidenciados na tabela 3. 
Pautando-se na tabela 3 , percebe-se que todas as variáveis obtiveram alfas de cronback situados acima de 0,7; o que demonstra uma forte consistência interna dos dados amostrados. Por outro lado, o teste de adequação de amostragem de Kaiser-Meyer-Olkin measure of sampling adequacy (KMO) mostra que os dados podem ser tratados por meio da análise fatorial exploratória. Exceto a variável "liderança", que obteve um valor para o KMO em torno de 0,60 (considerado medíocre, mas ainda aceitável), as demais variáveis tiveram valores próximos de 0,7 , revelando uma adequação razoável.

Tabela 3

Resultados da extração das dimensões

\begin{tabular}{|c|c|c|c|c|c|}
\hline Dimensões ou fatores & Codificação & $\alpha_{c}$ & $\begin{array}{l}\text { PEV } \\
(\%)\end{array}$ & KMO & $\begin{array}{c}\text { BTS } \\
\text { (valor-p) }\end{array}$ \\
\hline $\begin{array}{l}\text { 1. Capacidade } \\
\text { empreendedora }\end{array}$ & $C_{1}$ & 0,859 & 70,38 & 0,733 & $<0,0001$ \\
\hline $\begin{array}{l}\text { 2. Capacidade de trabalhar sob } \\
\text { pressão }\end{array}$ & $\mathrm{C}_{2}$ & 0,708 & 54,05 & 0,675 & $<0,0001$ \\
\hline 3. Criatividade & $\mathrm{C}_{3}$ & 0,766 & 61,74 & 0,763 & $<0,0001$ \\
\hline 4. Flexibilidade & $\mathrm{C}_{4}$ & 0,744 & 57,57 & 0,698 & $<0,0001$ \\
\hline 5. Liderança & $\mathrm{C}_{5}$ & 0,758 & 50,12 & 0,600 & 0,002 \\
\hline 6. Motivação & $\mathrm{C}_{6}$ & 0,749 & 57,71 & 0,682 & $<0,0001$ \\
\hline 7. Negociação & $\mathrm{C}_{7}$ & 0,806 & 63,91 & 0,691 & $<0,0001$ \\
\hline 8. Planejamento & $\mathrm{C}_{8}$ & 0,716 & 50,86 & 0,683 & $<0,0001$ \\
\hline 9. Visão sistêmica & $\mathrm{C}_{9}$ & 0,751 & 51,38 & 0,675 & $<0,0001$ \\
\hline $\begin{array}{l}\text { 10. Relacionamento } \\
\text { interpessoal }\end{array}$ & $\mathrm{C}_{10}$ & 0,832 & 67,72 & 0,673 & $<0,0001$ \\
\hline 11. Comunicação & $C_{11}$ & 0,891 & 53,14 & 0,687 & $<0,0001$ \\
\hline $\begin{array}{l}\text { 12. Identificação das } \\
\text { necessidades de tomada } \\
\text { de decisão }\end{array}$ & $\mathrm{PD}_{1}$ & 0,735 & 63,59 & 0,678 & $<0,0001$ \\
\hline $\begin{array}{l}\text { 13. Concepção: criação e } \\
\text { análise dos possíveis } \\
\text { cursos de ação }\end{array}$ & $\mathrm{PD}_{2}$ & 0,737 & 68,56 & 0,697 & $<0,0001$ \\
\hline $\begin{array}{l}\text { 14. Escolha por uma das } \\
\text { alternativas de ação }\end{array}$ & $\mathrm{PD}_{3}$ & 0,824 & 63,30 & 0,674 & $<0,0001$ \\
\hline $\begin{array}{l}\text { 15. Revisão: avaliação das } \\
\text { decisões tomadas }\end{array}$ & $\mathrm{PD}_{4}$ & 0,764 & 60,54 & 0,697 & $<0,0001$ \\
\hline
\end{tabular}


Além disso, o teste Bartlett test of sphericity (BTS) indica que a matriz de correlação tem aderência à matriz identidade. Os valores do referido teste evidenciam significância menor do que 0,0001 ( $<<0,0001$ ), indicando que houve um nível de probabilidade muito adequado para a correlação entre as variáveis e, portanto, o método de análise fatorial é confirmado como apropriado para o tratamento dos dados.

\section{Resultados da análise de regressão linear múltipla}

Na tabela 4 evidenciam-se as estimações econométricas dos parâmetros dos modelos, por meio da técnica de regressão linear múltipla. Consideraram-se para efeito de análise as significâncias estatísticas a partir do valor-p de cada parâmetro, ou usou-se a estatística t-student, além da análise do sinal de cada parâmetro individualmente.

A partir das fases do processo decisório descritas no questionário, foram estabelecidos quatro modelos, nos quais avalia-se o impacto das 11 competências estudadas sobre a efetividade em cada uma das referidas fases, a saber:

- modelo 1 - impacto das competências relativas à defesa aérea (C), na opinião dos trabalhadores, sobre a dimensão identificação das necessidades de tomada de decisão $\left(\mathrm{PD}_{1}\right)$;

v modelo 2 - impacto das competências relativas à defesa aérea (C), na opinião dos trabalhadores, sobre a dimensão concepção: criação e análise dos possíveis cursos de ação $\left(\mathrm{PD}_{2}\right)$;

v modelo 3 - impacto das competências relativas à defesa aérea (C), na opinião dos trabalhadores, sobre a dimensão escolha por uma das alternativas de ação $\left(\mathrm{PD}_{3}\right)$;

v modelo 4 - impacto das competências relativas à defesa aérea (C), na opinião dos trabalhadores, sobre a dimensão revisão: avaliação das decisões tomadas $\left(\mathrm{PD}_{4}\right)$.

Em todos os modelos estimados pelo método dos mínimos quadrados ordinários, as estatísticas F-snedecor foram significantes estatisticamente, exceto o modelo 3, representado pela variável dependente " $\mathrm{PD}_{3}$ ". Portanto, foi desprezada a sua análise, em função da aceitação da hipótese nula de não existência da regressão linear múltipla. Além disso, no modelo 3 não foi encontrada significância estatística entre todos os parâmetros estimados, dado que só foram considerados como significantes valores para o valor-p abaixo de 0,10. 
Avaliando-se os resultados auferidos para o modelo 1, percebe-se que as variáveis independentes que mais influenciam a variável dependente " $\mathrm{PD}_{1}$ ", ordenadas do maior para o menor impacto em termos das estatísticas t-student, foram: o relacionamento interpessoal $\left(\mathrm{C}_{10}\right)$; capacidade empreendedora $\left(\mathrm{C}_{1}\right)$; liderança $\left(\mathrm{C}_{5}\right)$; comunicação $\left(\mathrm{C}_{11}\right)$; e capacidade de trabalhar sob pressão $\left(\mathrm{C}_{2}\right)$. Todos os parâmetros estimados para esse modelo apresentaram sinais positivos, o que evidencia um relacionamento direto ou de mesmo sentido entre as variáveis independentes referentes às competências e a variável dependente "PD,". Além disso, o referido modelo apresentou um coeficiente de explicação ajustado aos graus de liberdade e sem o termo constante $\left(R^{2} \mathrm{Adj}\right)$ igual a $82,41 \%$, o que mostra um bom ajustamento para a variável dependente, já que apenas $17,59 \%$ das variações desta variável não puderam ser explicados pelas variáveis independentes (as competências).

Tabela 4

Estimação dos parâmetros dos modelos de regressão múltipla

\begin{tabular}{|c|c|c|c|c|c|}
\hline $\begin{array}{l}\text { Variáveis } \\
\text { dependentes }\end{array}$ & Parâmetros & $\hat{\beta}$ & Erro padrão & $t$-student & valor-p \\
\hline \multirow{4}{*}{ Modelo 1: $\mathrm{PD}_{1}$} & $\mathrm{C}_{1}$ & 0,925 & 0,218 & 4,238 & 0,002 \\
\hline & $\mathrm{C}_{2}$ & 0,307 & 0,130 & 2,363 & 0,042 \\
\hline & $\mathrm{C}_{3}$ & 0,303 & 0,224 & 1,355 & 0,208 \\
\hline & $\mathrm{C}_{4}$ & 0,040 & 0,148 & 0,269 & 0,794 \\
\hline \multirow[t]{2}{*}{$\mathrm{R}^{2} \mathrm{Adj}=82,41 \%$} & $\mathrm{C}_{5}$ & 0,515 & 0,140 & 3,690 & 0,005 \\
\hline & $\mathrm{C}_{6}$ & 0,051 & 0,148 & 0,343 & 0,739 \\
\hline \multirow[t]{2}{*}{$\mathrm{F}_{\mathrm{Cal}}=9,519$} & $\mathrm{C}_{7}$ & 0,091 & 0,172 & 0,531 & 0,608 \\
\hline & $\mathrm{C}_{8}$ & 0,046 & 0,165 & 0,281 & 0,785 \\
\hline \multirow[t]{3}{*}{$(p=0,047)$} & $\mathrm{C}_{9}^{\circ}$ & 0,042 & 0,144 & 0,289 & 0,779 \\
\hline & $C_{10}$ & 0,727 & 0,159 & 4,576 & 0,001 \\
\hline & $C_{11}$ & 0,426 & 0,144 & 2,955 & 0,016 \\
\hline \multirow{4}{*}{ Modelo 2: $\mathrm{PD}_{2}$} & $\mathrm{C}_{1}$ & 0,208 & 0,398 & 0,524 & 0,612 \\
\hline & $\mathrm{C}_{2}$ & 0,112 & 0,237 & 0,471 & 0,648 \\
\hline & $\mathrm{C}_{3}$ & 0,029 & 0,408 & 0,070 & 0,946 \\
\hline & $\mathrm{C}_{4}$ & 0,118 & 0,270 & 0,438 & 0,671 \\
\hline \multirow{2}{*}{$\begin{array}{l}\mathrm{R}^{2} \mathrm{Adj}= \\
34,34 \%\end{array}$} & $\mathrm{C}_{5}$ & 0,499 & 0,254 & 1,960 & 0,078 \\
\hline & $\mathrm{C}_{6}$ & 0,141 & 0,270 & 0,523 & 0,612 \\
\hline \multirow{2}{*}{$\mathrm{F}_{\mathrm{Cal}}=2,168$} & $\mathrm{C}_{7}$ & 0,251 & 0,313 & 0,803 & 0,441 \\
\hline & $\mathrm{C}_{8}$ & 0,347 & 0,301 & 1,150 & 0,277 \\
\hline \multirow[t]{3}{*}{$(p=0,0987)$} & $\mathrm{C}_{9}$ & 0,290 & 0,263 & 1,104 & 0,295 \\
\hline & $C_{10}$ & 0,220 & 0,289 & 0,759 & 0,465 \\
\hline & $C_{11}$ & 0,064 & 0,263 & $-0,245$ & 0,812 \\
\hline
\end{tabular}




\begin{tabular}{|c|c|c|c|c|c|}
\hline $\begin{array}{l}\text { Variáveis } \\
\text { dependentes }\end{array}$ & Parâmetros & $\hat{\beta}$ & Erro padrão & t-student & valor-p \\
\hline \multirow{4}{*}{ Modelo 3: $\mathrm{PD}_{3}$} & $\mathrm{C}_{1}$ & 0,705 & 0,406 & 1,739 & 0,113 \\
\hline & $\mathrm{C}_{2}$ & 0,237 & 0,241 & 0,981 & 0,350 \\
\hline & $\mathrm{C}_{3}$ & 0,452 & 0,416 & 1,088 & 0,302 \\
\hline & $\mathrm{C}_{4}$ & 0,257 & 0,275 & 0,935 & 0,372 \\
\hline \multirow[t]{2}{*}{$\mathrm{R}^{2} \mathrm{Adj}=27,39 \%$} & $\mathrm{C}_{5}$ & 0,226 & 0,259 & 0,873 & 0,403 \\
\hline & $\mathrm{C}_{6}$ & 0,147 & 0,276 & 0,533 & 0,606 \\
\hline $\mathrm{F}_{\mathrm{Cal}}=1,686$ & $\mathrm{C}_{7}$ & 0,061 & 0,319 & 0,192 & 0,851 \\
\hline \multirow{4}{*}{$(p=0,1532)$} & $\mathrm{C}_{8}$ & 0,225 & 0,307 & 0,733 & 0,481 \\
\hline & $\mathrm{C}_{9}$ & 0,085 & 0,268 & 0,317 & 0,758 \\
\hline & $C_{10}$ & 0,335 & 0,295 & 1,136 & 0,282 \\
\hline & $C_{11}$ & 0,042 & 0,268 & 0,158 & 0,877 \\
\hline \multirow{4}{*}{ Modelo 4: $\mathrm{PD}_{4}$} & $\mathrm{C}_{1}$ & 0,412 & 0,390 & 1,056 & 0,316 \\
\hline & $\mathrm{C}_{2}$ & 0,418 & 0,232 & 1,801 & 0,100 \\
\hline & $\mathrm{C}_{3}$ & 0,211 & 0,400 & 0,526 & 0,610 \\
\hline & $\mathrm{C}_{4}$ & 0,525 & 0,265 & 1,983 & 0,075 \\
\hline \multirow{2}{*}{$\begin{array}{l}\mathrm{R}^{2} \mathrm{Adj}= \\
35,66 \%\end{array}$} & $C_{5}^{4}$ & 0,248 & 0,250 & 0,994 & 0,344 \\
\hline & $\mathrm{C}_{6}$ & 0,253 & 0,265 & 0,952 & 0,364 \\
\hline \multirow{2}{*}{$\mathrm{F}_{\mathrm{Cal}}=2,231$} & $\mathrm{C}_{7}$ & 0,045 & 0,307 & 0,147 & 0,886 \\
\hline & $\mathrm{C}_{8}$ & 0,120 & 0,296 & 0,407 & 0,693 \\
\hline \multirow[t]{3}{*}{$(p=0,876)$} & $\mathrm{C}_{9}$ & 0,142 & 0,258 & 0,550 & 0,595 \\
\hline & $C_{10}$ & 0,178 & 0,284 & 0,626 & 0,545 \\
\hline & $C_{11}$ & 0,151 & 0,258 & 0,584 & 0,572 \\
\hline
\end{tabular}

Nota: Os valores em negrito têm boas significâncias estatísticas.

Avaliando-se, com base na tabela 4, o modelo 2, percebeu-se, por meio da estatística $t$-student, que apenas a variável liderança " $\mathrm{C}_{5}$ " impacta a variável " $\mathrm{PD}_{2}$ ", considerando um valor-p igual a 0,078. As demais variáveis analisadas do modelo foram consideradas estatisticamente desprezíveis. Vale destacar que esse modelo apresentou um coeficiente de explicação ajustado aos graus de liberdade e sem o termo constante ( $R^{2}$ Adj) igual a 34,34\%, considerado um modelo com baixo grau de ajustamento.

Quanto ao modelo 4, ainda tomando como base a Tabela 4, percebeuse por meio da estatística t-student que a variável capacidade de trabalhar sob pressão $\left(\mathrm{C}_{2}\right)$ impacta a variável dependente " $\mathrm{PD}_{4}$ ", considerando um valor-p igual a 0,100 . Outra variável que impacta em " $\mathrm{PD}_{4}$ " refere-se à flexibilidade $\left(\mathrm{C}_{4}\right)$ cuja estatística $t$-student foi igual a 1,983, com um valor-p associado a tal estatística igual a 0,075. As demais variáveis analisadas no modelo foram 
consideradas estatisticamente desprezíveis. Esse modelo apresentou ainda um coeficiente de explicação ajustado aos graus de liberdade e sem o termo constante $\left(\mathrm{R}^{2}\right.$ Adj) igual a $35,66 \%$, sendo visto como um modelo com um baixo grau de ajustamento.

\section{Discussão dos resultados}

A análise fatorial exploratória, seguida da análise de regressão linear múltipla, permitiu relacionar as fases do processo decisório, segundo o modelo de Simon (1970), a competências consideradas relevantes, com base em Gramigna (2002). Os resultados propiciados pela análise representam o impacto das competências sobre cada uma das fases, cabendo descrever aquelas que se mostraram estatisticamente relevantes.

Na primeira fase do processo decisório, destinada à identificação da necessidade de tomada de decisão, há indícios de que os indivíduos cuja avaliação aponte bom desempenho no relacionamento interpessoal tenham maior probabilidade de efetividade. A esses sujeitos, seguem-se aqueles em quem são observadas competências relativas à capacidade empreendedora, liderança, comunicação e capacidade de trabalhar sobre pressão.

Já na fase seguinte, relativa à criação e análise dos possíveis cursos de ação, evidenciou-se o impacto da variável liderança. Chama a atenção o fato de ações criativas usualmente estarem correlacionadas a competências como criatividade e visão sistêmica, o que não ocorreu neste artigo. Entretanto, o resultado encontrado revela uma dinâmica própria da atividade de defesa aérea, pois observações realizadas no ambiente operacional já apontavam para a valorização da liderança exercida pelo AJCC, graduado reconhecido pelo grupo como supervisor das atividades.

Curiosamente, não foram encontradas evidências do impacto das competências elencadas por Gramigna (2002) como essenciais ao serviço público sobre a atuação do oficial, concentrada na fase de escolha por uma das alternativas de ação. A partir dos resultados oriundos da análise estatística, confirmou-se que não é nesta fase que a liderança tem maior impacto, como era de se esperar em se considerando a cultura organizacional, na qual se atribui a capacidade e função de liderança ao oficial.

Na última fase, referente à avaliação da decisão tomada, a capacidade de trabalhar sobre pressão e a flexibilidade se mostram importantes competências, capazes de predizer uma performance efetiva por parte dos sujeitos em quem são evidenciadas tais características. 
A verificação do impacto das referidas competências sobre as fases específicas do processo decisório permite que sejam estabelecidos programas voltados especificamente ao desenvolvimento dessas competências, preditoras de incremento nos resultados da organização estudada. Quanto ao desenvolvimento dos oficiais, que ocupam os níveis hierárquicos mais altos da organizaçação, não foi possível correlacionar a efetividade da tomada de decisão com as competências em estudo. Já no que concerne a programas destinados ao desenvolvimento dos graduados, indivíduos que ocupam os níveis intermediários das Forças Armadas, este artigo aponta questões que devem ser alvo de atenção.

\section{Considerações finais}

Com o objetivo de avaliar o impacto das competências consideradas essenciais para o desempenho das atividades de defesa aérea sobre a efetividade do processo decisório, foi feito um estudo que deu origem a este artigo. Os resultados podem subsidiar os gestores nas decisões relativas à alocação de pessoal e formação de equipes, possibilitando um maior alinhamento entre as competências individuais e os interesses organizacionais — tal seja, alinhando as práticas de gestão de pessoas com a estratégia organizacional.

É importante mencionar o interesse demonstrado pelos gestores do órgão estudado em dar um caráter científico à questão dos recursos humanos, considerando a possibilidade de que outras práticas possam levá-los a cumprir com mais efetividade a missão de defender o espaço aéreo e competir com os seus concorrentes - que são os países com quem competem por poder no cenário mundial. Tal disposição por parte dos gestores revelou-se no fornecimento imediato das informações que lhes foram solicitadas, na autorização de livre acesso ao respectivo efetivo e, ainda, na autorização para divulgação dos dados. Essa disposição pode ser considerada um indício da transformação, descrita por Dutra (2004), quanto ao perfil exigido pelo mercado, que passou de obediente e disciplinado para autônomo e empreendedor.

Essa mudança de perfil, em que são valorizadas capacidades potenciais de desenvolvimento, pressupõe uma cultura que estimula a iniciativa dos indivíduos. Assim, talvez seja o momento de repensar se o espaço destinado ao graduado é adequado para o alcance dos objetivos organizacionais. Não se trata de questionar a precedência hierárquica, mas de considerar que a sociedade do conhecimento exige que se esteja em constante processo de aprendizagem para fazer frente a um ambiente em constante mutação; portanto, esta- 
belecer limites para o desenvolvimento das pessoas seria andar na contramão. O Estatuto dos Militares define que a tomada de decisão dos graduados ocorre apenas no nível técnico, sendo o nível estratégico sempre tarefa de oficiais. Aos graduados, portanto, é destinado o nível de execução, podendo incluir a assessoria técnico-operacional. Em uma época na qual investir em capital intelectual se mostra indispensável como forma de capacitação para o enfrentamento dos novos problemas que o ambiente apresentar, tais limites parecem se enfraquecer, uma vez que a preparação para a assunção de cargos estratégicos exige que sejam desenvolvidas competências durante toda a carreira.

Figueiredo (2005) aponta a presença de hierarquia rígida como um dos obstáculos ao conhecimento, junto com a alocação indevida de recursos e falta de alinhamento das expectativas. Não se pretende aqui colocar em cheque os preceitos constitucionais de hierarquia e disciplina, base das Forças Armadas, mas apontar a necessidade de construção de um caminho próprio para inclusão na sociedade do conhecimento. Figueiredo (2005:45) considera a gestão do conhecimento capaz de amenizar tais problemas ao prover "mecanismos e procedimentos dedicados a estimular a formação de competências e prover a ampliação generalizada do conhecimento relevante". Portanto, o estabelecimento das competências que afetam a efetividade do processo decisório na defesa aérea pode resultar em benefícios à organização, desde que seja parte de um programa maior relativo aos programas de treinamento e desenvolvimento.

Sabe-se, ainda, que para a implementação da gestão por competências recomenda-se que todas as práticas de recursos humanos estejam alinhadas à estratégia da organização (Lawler III, 1994; Gramigna, 2002; Hamel e Prahalad, 2005). A concepção burocrática de recursos humanos vigente nas Forças Armadas, no entanto, não permite que se incorporem esses conhecimentos da mesma forma que vêm sendo adotados em empresas constituídas sobre outros princípios.

No caso da organização em estudo, é inviável considerar a possibilidade de outra forma de seleção que não o concurso público, pois isso implicaria mudanças na Constituição Federal. O mesmo ocorre com a remuneração variável, que exigiria alterações nas leis federais, na legislação militar, além de ir contra uma cultura fortemente arraigada, na qual a antiguidade ainda pesa mais que o merecimento. Acredita-se, entretanto, haver a possibilidade de conscientização acerca da necessidade de que as indicações para ocupação de funções e para a realização de cursos de carreira passem a ser decorrentes de critérios objetivos de avaliação de desempenho, baseados na contribuição das competências individuais para o fortalecimento das competências essenciais da organização. E, nesse sentido, este artigo pode ser um 
passo importante para o assentamento desta proposta no âmbito da cultura organizacional.

Quanto à funcionalidade dos achados neste estudo, há de se considerar tanto o alerta de Dutra (2004), para quem o conceito de competências, apesar de ser um avanço importante, não é suficiente para lidar com a complexidade organizacional, quanto as considerações de Gramigna (2002), relativas à importância de que, na definição dos perfis de competências compatíveis com os postos de trabalho, haja flexibilidade. Os perfis de competência estabelecidos para cada função têm caráter transitório, já que o conteúdo dos postos se modifica perante novas demandas. Como exemplo, poder-se-ia citar a mudança de tecnologia em curso no Centro de Operações Militares em estudo: o novo sistema tem forma diferente de apresentar as informações, alterando a interface homem-máquina, o que pode resultar na necessidade de novas habilidades. Com base na experiência de outros órgãos, presume-se que isso deverá ser mais marcante no que diz respeito à inserção de dados no sistema, onde a habilidade de digitação passa a ser fundamental. Percebe-se, portanto, a possibilidade de que venha a ocorrer uma quebra no ritmo de trabalho, até que os controladores estejam adaptados à nova configuração. Aponte-se aqui que essa substituição nos equipamentos pode, inclusive, exigir que sejam revistos os achados deste estudo. Nesse caso, o artigo não terá sido em vão, pois, de posse das informações aqui contidas, será possível estabelecer um estudo comparativo entre as competências exigidas para o processo decisório, com base em cada um dos sistemas tecnológicos empregados.

Como fator limitante a esta pesquisa, considera-se o tamanho da amostra obtida entre o universo de 46 indivíduos. Foi preservado o critério sugerido por Hair Jr. e colaboradores (1998) de proporcionalidade mínima exigida de cinco dados para cada variável analisada, a saber: Ctam, Coam, AJCC e CC. Ao obter um total de respondentes igual a 21 trabalhadores, essa proporcionalidade foi preservada, mas não deixou de ser uma limitação do trabalho, que deve ser considerada no desenvolvimento de novos estudos.

Com relação ao tema abordado, há uma limitação decorrente do caráter confidencial de toda a legislação que trata de Segurança Nacional, na qual estão incluídas as atividades de defesa aérea. Gramigna (2002) salientou a necessidade de que se tenham todas as atividades das unidades descritas de forma objetiva antes de se estabelecer qualquer prática relativa à gestão por competências. No caso investigado neste artigo, a legislação que versa sobre as atividades desempenhadas é de cunho confidencial, o que impede a livre divulgação no meio acadêmico, mas não impossibilita que tal critério seja cumprido, já que os responsáveis por uma eventual implementação seriam 
militares com acesso aos materiais confidenciais. Tais restrições são citadas por Probst e colaboradores (2002), ao discutirem disseminação e compartilhamento de informações: há conhecimentos que necessitam ficar em segredo, por questões de competitividade. Sem dúvida, é o caso de informações relativas à defesa nacional, no caso defesa aeroespacial. Tal perspectiva tem apoio, também, na definição de estratégia proposta por Mintzberg e colaboradores (2000), na qual uma das possibilidades é compreendê-la como um truque, uma manobra para enganar um oponente: o sucesso do trabalho de defesa aérea depende do oponente desconhecer as táticas utilizadas, para ser pego de surpresa e barrado em sua intenção de invadir o espaço aéreo brasileiro.

\section{Referências}

ANTONACOPOULOU, E.; PAPAMICHAIL, N. Knowledge flows in decision-making and learning. The STDL Framework, 2004.

BABBIE, E. R. Métodos de pesquisa de survey. Belo Horizonte: UFMG, 1999.

BARNARD, C. I. As funções do executivo. São Paulo: Atlas, 1979.

BARNEY, J. B. Firm resources and sustained competitive advantage. Journal of Management, v. 17, p. 99-120, 1991.

; ARIKAN, A. M. The resource-based view: origins and implications. In: HITT, M. A.; FREEMAN, R. E.; HARRISON, J. S. The blackwell handbook of strategic management. Oxford: Blackwell Publishers, 2001.

DUTRA, J. S. Competências: conceitos e instrumentos para a gestão de pessoas na empresa moderna. São Paulo: Atlas, 2004.

FELIX, C. L. A prática de competências gerencias no setor público. Revista de Administração Pública, Rio de Janeiro, v. 39, n. 2, p. 255-78, mar./abr. 2005.

FIGUEIREDO, S. Gestão do conhecimento: estratégias competitivas para a criação e mobilização do conhecimento na empresa. Rio de Janeiro: QualityMark, 2005.

FORÇA AÉREA BRASILEIRA. Disponível em: < www.fab.mil.br/imprensa/Noticias/ lei-abate/3007_abate.htm7Y>.

GIL, A. C. Como elaborar projetos de pesquisa. São Paulo: Atlas, 2002.

GODOY, A. S. Introdução à pesquisa qualitativa e suas possibilidades. Revista de Administração de Empresas, v. 35, n. 2, p. 57-63, 1995.

GOMES, D. M. Competências e habilidades do diretor. Campo Grande: UCDB, 2003. 
GRAMIGNA, M. R. Modelo de competências e gestão de talentos. São Paulo: Makron Books, 2002.

HAIR, J. F. et al. Multivariate data analysis. 5. ed. New Jersey: Prentice Hall, 1998.

HAMEL, G.; PRAHALAD, C. K. Competindo pelo futuro. Rio de Janeiro: Campus, 2005.

HARRISON, J. S. Administração estratégica de recursos e relacionamentos. Porto Alegre: Bookman, 2005.

JORDAN, R. A. Reflecting on the military's best practices. Human Resource Management, v. 46, n. 1, p. 143-146, Spring 2007.

KUTNER, M. H. et al. Applied linear models. 5. ed. New York: McGraw-Hill Irwin, 2005.

LAWLER III, E. E. From job-based to competency-based organizations. Journal of Organizational Behavior, v. 15, p. 3-15, 1994.

MINTZBERG, H.; AHLSTRAND, B.; LAMPEL, J. Safári de estratégia: um roteiro pela selva do planejamento estratégico. Porto Alegre: Bookman, 2000.

; RAISIGHANI, D.; THERET, A. The structure of unstructured decision processes. Administrative Science Quarterly, v. 21, n. 2, p. 246-275, June 1976.

MOTTA, P. R. Gestão contemporânea: a ciência e a arte de ser dirigente. Rio de Janeiro: Record, 1996.

MOURA, M. C.; BITENCOURT, C. C. A articulação entre estratégia e o desenvolvimento de competências gerenciais. RAE-Eletrônica, v. 5, n. 1, jan./jun. 2006.

PEREIRA, J. C. R. Análise de dados qualitativos - estratégias mercadológicas para as ciências da saúde, humanas e sociais. 3. ed. São Paulo: Universidade de São Paulo, 2001.

PROBST, G.; RAUB, S.; ROMHARDT, K. Gestão do conhecimento: os elementos construtivos do sucesso. Porto Alegre: Bookman, 2002.

RICHARDSON, R. J. Pesquisa social: métodos e técnicas. São Paulo: Atlas, 1985.

SIMON, H. Comportamento administrativo: estudo dos processos decisórios nas organizações administrativas. Rio de Janeiro: FGV, 1970.

. Bounded rationality. In: EATWELL, J.; MILGATE M.; NEWMAN, P. The new palgrave dictionary of economics. Londres: Macmillan, 1987. 
SOUZA, E. C. A capacitação administrativa e a formação de gestores governamentais. Revista de Administração Pública, Rio de Janeiro, v. 36, n. 1, p. 73-88, jan./fev. 2002.

SPECTOR, P. E. Psicologia nas organizações. São Paulo: Saraiva, 2004.

STEWART, T. Capital intelectual: a nova vantagem competitiva das empresas. Rio de Janeiro: Campus, 1998.

YIN, R. Estudo de caso: planejamento e métodos. Porto Alegre: Bookman, 2001. 